\author{
Jakub Wilk \\ ORCID: 0000-0002-1505-1949 \\ Uniwersytet Wrocławski \\ Łukasz Śmigiel \\ ORCID: 0000-0001-7821-9430 \\ Uniwersytet Wrocławski \\ https://doi.org/10.19195/1733-5779.38.23
}

\title{
Analiza aktualności Radia Nowy Świat i Radia 357
}

Słowa kluczowe: radio, aktualności, internet, treści online, aplikacje, komunikacja, radiowy kontent, parateksty, wiadomości, dyskurs, analiza dyskursu

Keywords: radio, news, Internet, online content, applications, communication, radio content, paratexts, news, discourse, discourse analysis

Abstrakt: W węższym ujęciu artykuł podejmuje analizę zbiorów krótkich tekstów opublikowanych przez stacje radiowe Radio Nowy Świat (RNS) oraz Radio 357 (357) w działach poświęconych aktualnym wydarzeniom (w przedziale czasowym 1 lutego-31 marca 2021). Teksty te tworzą korpusy poddane analizie ilościowej i analizie jakościowej. Wyniki prowadzonych obserwacji zestawione zostały na zasadach komparatystyki. W ujęciu szerszym — poprzez zaprezentowaną tu analizę autorzy tekstu przyglądają się przemianom radiowych paratekstów (które są już być może zupełnie nowymi, samodzielnymi komunikatami, a nie jedynie dodatkiem do antenowych przekazów medialnych).

\section{Analysis of the news of Radio Nowy Świat and Radio 357}

Abstract: In a narrow sense, the text concerns the analysis of collections of short texts published by radio stations Radio Nowy Świat (RNS) and Radio 357 (357), in sections devoted to current events (in the period 01/02/2021-31/03/2021). These texts form corpuses subject to quantitative and qualitative analyses; and the results of the conducted observations were compiled on the basis of comparative studies. In a broader sense - through the analysis presented here, the authors of the text look at the changes in radio paratexts (which are perhaps completely new, independent messages, and not only an addition to aerial media messages). 


\section{Wprowadzenie}

Internet w ciągu lat stał się prawdziwie złożonym i wielopoziomowym systemem medialnym. Derrick de Kerckhove wskazuje na wyróżniające to medium cechy, którymi są multimedialność (integracja wszystkich dostępnych form przekazu) i hipertekstowość (powiązanie różnorakich treści siecią logicznych, przyczynowo-skutkowych relacji, zwanych hiperłączami) ${ }^{1}$. W początkach rozbudowy infrastruktury internetowej opartej na protokole przesyłania dokumentów hipertekstowych, czyli HTTP (obecnie w postaci szyfrowanych protokołów HTTPS), sieć stron WWW od strony rozwiązań technicznych i informatycznych nie była jeszcze gotowa na przeformatowanie do postaci nowych kanałów dystrybucji mediów tradycyjnych - prasy, radia i telewizji. Potrzeba było czasu, aby sieć stała się zbiorem mniejszych węzłów, którymi Manuel Castells w Społeczeństwie sieci nazywał między innymi:

systemy telewizyjne, studia rozrywkowe, środowiska tworzące grafikę komputerową, nowe zespoły i przenośne urządzenia wytwarzające, transmitujące i odbierające sygnały w globalnej sieci nowych mediów, która leży u korzeni kulturowej ekspresji i opinii publicznej w Wieku informacji²

Dzięki rozbudowie internetu, jego sieci wzajemnych zależności już od kilku lat trwa ekspansja konkretnych nadawców w przestrzeni online. Jeszcze w 2016 roku „Rzeczpospolita” cytowała Mirosława Godlewskiego, starszego doradcę w Boston Consulting Group odpowiedzialnego za sektor TMT. Ekspert potwierdzał, że medialni klienci

od dawna uważali, że taka zmiana w końcu kiedyś na rynku nastąpi, a potem stanie się standardem, podobnie jak jest nim dziś sprzedawanie muzyki poprzez serwisy streamingowe, takie jak Spotify. Użytkownik ceni sobie wygodę, a żadne inne medium nie daje mu dziś takiej swobody jak Internet ${ }^{3}$.

Dodajmy, że niespełna dwa lata później ten sam tytuł prasowy cytował fragmenty raportu analityków z Perspectives from the Global Entertainment \& Media Outlook 2018-2022, informując, że z kolei dla wydawców prasy wyzwaniem pozostaje zwiększenie liczby czytelników płatnych serwisów internetowych i osiąganie większych przychodów z działalności w sieci ${ }^{4}$. Internet powoli, ale sukcesywnie staje się również platformą do słuchania radia. Jak pokazują analizy słuchalności stacji radiowych w Polsce Radio Track Millward Brown, opracowane przez por-

${ }^{1}$ D. de Kerckhove, Inteligencja otwarta. Narodziny społeczeństwa sieciowego, Warszawa 2001, s. 22.

2 M. Castells, Spoleczeństwo sieci, Warszawa 2007, s. 468.

${ }^{3}$ L. Lemańska, Płatne telewizje przenosza się do Internetu, https://www.rp.pl/Media-i-internet/311299867-Platne-telewizje-przenosza-sie-do-internetu.html (dostęp: 10.06.2021).

${ }^{4}$ U.Zielińska, Świat mediów przenosi się do sieci, https://www.rp.pl/Media-i-internet/181019437-PwC-swiat-mediow-przenosi-sie-do-sieci.html (dostęp: 10.06.2021). 
tal Wirtualnemedia.pl, w roku 2017 odnotowano, że już 7,4\% \% $^{5}$ Polaków słuchało radia przez internet, a według „Raportu Radio 2020 — Podsumowanie wyników słuchalności”, poziom ten w 2020 roku osiągnął $9 \% 6$.

Wraz z radiem do internetu przenoszą się również towarzyszące temu medium parateksty, które ewoluują w ciekawych kierunkach, zyskują zupełnie nowe formy. My zaś obserwujemy zmianę sensu ich wykorzystania $\mathrm{w}$ ramach medialnego przekazu. Jak pisze Iwona Loewe w książce Gatunki paratekstowe w komunikacji medialnej:

Przez paratekst rozumiemy taki tekst, który eskortuje tekst właściwy, bazę, tekst pełny, wytwór działalności kulturowej człowieka, często wielokodowy, w którym jednak udział (mniej lub bardziej znaczący) ma kod werbalny. Paratekst ma za zadanie uczynić korpus tekstu łatwo dostępny w projektowanym dla niego środowisku odbiorczym, a środowisko to uczynić jak najliczniejszym. W tym celu ma zaprezentować tekst właściwy (w tożsamym środowisku nadawczym) i zachęcić do jego odbioru, pozostawiając możliwość interpretacji samemu odbiorcy?

Internet wydaje się doskonałym miejscem do rozbudowania medialnej struktury radia, do uczynienia go tworem bardziej multimedialnym i poszerzonym o towarzyszące mu parateksty. Zarówno strony WWW stacji radiowych w internecie, jak i towarzyszące tym stacjom aplikacje stworzone na urządzenia mobilne skutecznie obudowują to medium dodatkowymi funkcjami i multimediami.

$\mathrm{Na}$ stronach internetowych stacji radiowych przeczytamy teksty publicystyczne, transkrypcje rozmów przeprowadzonych na antenie, zobaczymy specjalnie przygotowane fotografie, które komentują tekst (odnoszący się do radiowego dźwięku). Część materiałów z anteny FM w wersji rozbudowanej pojawia się na stronach WWW albo we wspomnianych aplikacjach rozgłośni radiowej, na przykład rozbudowane wersje rozmów z politykami w radiu RMF FM z cyklu „Poranna rozmowa w RMF FM z Robertem Mazurkiem”. Obecnie zarówno poprzez aplikacje, jak i na stronach WWW dostępne są materiały wideo, przekaz wideo na żywo ze studia radiowego czy przekierowanie do radiowej playlisty zawieszonej na jednej z popularnych platform streamingowych. Iwona Loewe w swoich analizach wymieniała przed laty jako najczęściej spotykane w radiu gatunki paratekstowe zajawkę, zapowiedź oraz headline news ${ }^{8}$. Wydaje się, że w świecie radiowych paratekstów (teraz obejmujących także znacznie rozbudowane formy działalności stacji radiowych online) następują sukcesywne przemiany. Symbolem tych przemian może być przeprowadzona ze sporym sukcesem w 2017 roku akcja Radia Eska, które promowało swoją mobilną aplikację. Ogłoszono wtedy

5 M. Kurdupski, Wyniki stuchalności, https://www.wirtualnemedia.pl/artykul/rynek-radiowy-w-2018-roku-zasieg-czas-miejsce-sluchania (dostęp: 10.06.2021).

${ }^{6}$ IloveRadioPL, Raport Radio 2020, https://iloveradio.pl/wp-content/uploads/2021/02/RADIO2020_raport-ILR-1.pdf (dostęp: 10.06.2021).

7 I. Loewe, Gatunki paratekstowe w komunikacji medialnej, Katowice 2007, s. 23.

8 Ibidem, s. 172. 
tak zwany Sezon na Jabłka i nagradzano produktami marki Apple osoby słuchające Radia ESKA za pośrednictwem aplikacji w smartfonie. W wyniku tych działań dwukrotnie wzrosła średnia dzienna liczba instalacji aplikacji Radia ESKA ${ }^{9}$. Obecnie aplikacje rozgłośni radiowych (umożliwiające słuchanie streamingów online) oferują rozbudowany, dodatkowy kontent: newsy, podcasty, treści wideo, listy hitów, informacje o nowościach muzycznych, możliwość sprawdzenia, co było lub będzie grane ${ }^{10}$. Szczególnie interesujące - jako podstawa do odnalezienia ich nowej formy w przestrzeni online - wydają się wspomniane headline newsy. W postaci klasycznej, na antenie radia mówionego, są to skróty wiadomości podawanych w regularnych serwisach radiostacji. Na teksty tego rodzaju składają się trzy informacje wybrane przez prezentujących, które nie tyle pojawiają się w postaci skróconego zdania (czysta kompresja), ile zostają zmodyfikowane tak, aby zatrzymać uwagę radiosłuchacza ${ }^{11}$. Obecnie, w sferze rozbudowanego contentu otaczającego rozgłośnie radiowe online, headline newsy przybierają formę aktualności, które trafiają w formie pisanej, obudowanej atrakcyjną dla oka grafiką na stronę WWW radia oraz do mobilnej aplikacji. Aktualności te w formie słowa mówionego pojawiają się także na antenie radiowej. W poniższym tekście analizie zostały poddane zbiory tych krótkich tekstów, pochodzące z działów poświęconych aktualnym wydarzeniom, zaczerpnięte ze stron WWW dwóch stacji radiowych ograniczających swoją działalność jedynie do sfery nadawczej online.

\section{Radio Nowy Świat oraz Radio 365. Zarys charakteru nadawczego rozgłośni}

Obu stacji radiowych można słuchać jedynie online. Jako pierwsze — regularne emisje rozpoczęło Radio Nowy Świat (RNS). Działalność radia rozpoczęła się wraz z audycją Wojciecha Manna „Poranna Manna” z 10 lipca 2020.

W dniu debiutu stacji 266 tys. unikalnych użytkowników [UU] słuchało jej za pośrednictwem strony internetowej nowyswiat.online. Kolejne 100 tys. UU włączyło radio poprzez Open FM. Dalej - 70 tys. UU w Replaio Radio i 15 tys. w aplikacji Patronite Audio [...]. Przygotowaną przez The House of Code aplikację Radia Nowy Świat, dostępną na iOS i Androida, pobrano ponad 41 tys. razy ${ }^{12}$.

Działalność rozgłośni finansowana jest z wpłat osób prywatnych oraz firm za pośrednictwem portalu Patronite. W czerwcu 2021 roku wsparcie wynosiło

9 K. Bartosz, Radio coraz bardziej mobilne, https://iloveradio.pl/radio-coraz-bardziej-mobilne-analiza/ (dostęp: 10.06.2021).

10 Ibidem.

11 I. Loewe, op. cit., s. 171.

12 M. Protaziuk, Radio Nowy Świat lepsze niż BBC Online, https://kultura.gazeta.pl/kultu$\mathrm{ra} / 7,114526,26124143$, radio-nowy-swiat-lepsze-niz-bbc-online-sa-oficjalne-wyniki.html (dostęp: 10.06.2021). 
632 tys. złotych przy udziale 30445 patronów ${ }^{13}$. Radio ma profil muzyczno-publicystyczny, koncentruje się na programach autorskich, nie emituje reklam i nie zaprasza na rozmowy polityków.

Tabela 1. Kanały streamingów Radia Nowy Świat

\begin{tabular}{|c|c|c|}
\hline Aplikacje mobilne & Platformy internetowe & Telewizje \\
\hline $\begin{array}{l}\text { Radio Nowy Świat } \\
\text { (Google Play, App Store) } \\
\text { — obsługa Chromecast } \\
\text { i AirPlay; } \\
\text { Patronite Audio (Google } \\
\text { Play, App Store); } \\
\text { Replaio Radio (Google } \\
\text { Play) - obsługa } \\
\text { Chromecast; } \\
\text { Online Radio Box } \\
\text { (Google Play, App } \\
\text { Store); } \\
\text { VRadio (Google Play, } \\
\text { App Store) - obsługa } \\
\text { DLNA, Audiocast, } \\
\text { Chromecast; } \\
\text { Triode (App Store } \\
\text { - iOS, App Store- } \\
\text { macOS) }\end{array}$ & $\begin{array}{l}\text { TuneIn; } \\
\text { Open FM (Google Play, } \\
\text { App Store); } \\
\text { WP Pilot (Google Play, } \\
\text { App Store); } \\
\text { airable.radio; } \\
\text { Frontier Nuvola; } \\
\text { mediaU - poz. 278 na } \\
\text { liście stacji z Polski; } \\
\text { myTuner Radio (Google } \\
\text { Play, App Store); } \\
\text { radio.garden; } \\
\text { radio.net; } \\
\text { radio-browser.info; } \\
\text { radio-polska.pl; } \\
\text { radiosure.com; } \\
\text { Reciva; } \\
\text { Sonos (serwis myTuner } \\
\text { Radio, Radio. } \\
\text { net); } \\
\text { Volumio - dostępna } \\
\text { jest wtyczka dla Radia } \\
\text { Nowy Świat; } \\
\text { Yamaha MusicCast; } \\
\text { vTuner }\end{array}$ & $\begin{array}{l}\text { Radio+ dla abonentów posiadających } \\
\text { dekodery CANAL+ podłączone do } \\
\text { internetu (pod numerem 588); } \\
\text { telewizja kablowa ASTA-NET; } \\
\text { telewizja kablowa Bart-Sat — poz. } 668 \\
\text { i 906; } \\
\text { telewizja kablowa BTK — poz. } 194 \\
\text { (DVB-T); } \\
\text { telewizja kablowa Domtel — poz. } 78 \\
\text { (DVB-T); telewizja kablowa ELSAT - } \\
\text { poz. 810; } \\
\text { telewizja kablowa Jambox — poz. 994; } \\
\text { telewizja kablowa KSM Bielsko-Biała - } \\
\text { poz. 161; } \\
\text { telewizja kablowa SAT FILM - } \\
\text { poz. 516; } \\
\text { telewizja kablowa TEL-KAB - poz. } 7 \\
\text { (IPTV) i poz. 912 (DVB-C); } \\
\text { telewizja kablowa Toruń - poz. 989; } \\
\text { telewizja kablowa TOYA; } \\
\text { telewizja kablowa TTUKST Trzcianka } \\
\text { - poz. 565; } \\
\text { telewizja kablowa TVK Hajnówka - } \\
\text { poz. 219; } \\
\text { Amazon Alexa - skill }\end{array}$ \\
\hline
\end{tabular}

Źródło: opracowanie własne.

Druga stacja radiowa, której aktualności ze strony WWW zostały poddane analizie w niniejszym tekście, to Radio 357 (357), nawiązujące swoją nazwą do warszawskiego adresu Rozgłośni Radiowej Programu Trzeciego (Myśliwiecka 3/5/7). Radio 357 rozpoczęło emisje pierwszych próbnych audycji 16 października 2020 od audycji „Pierwsze schodki do nieba”, poprowadzonej przez Piotra Stelmacha. Po kilkunastu testowych programach regularne emisje ruszyły 5 stycznia 2021. W poniedziałek 3 maja wyemitowano „Polski Top Radia 357”, który został poprowadzony przez Marcina Łukawskiego, Marka Niedźwiedzkiego i Piotra Stelmacha. Jak podaje portal Wirtualnemedia.pl — dwunastogodzinnej audycji „Polski Top Radia 357” „łącznie słuchano na 262 tys. urządzeń (dane dotyczą nume-

13 https://patronite.pl/radionowyswiat (dostęp: 10.06.2021). 
rów IP), w szczycie między 20.00 a 21.00 przy odbiornikach pozostało 86 tys. słuchaczy w 81 krajach na świecie"14. Podobnie jak w przypadku Radia Nowy Świat, działalność rozgłośni finansowana jest z wpłat osób prywatnych oraz firm za pośrednictwem portalu Patronite. Dodatkowo jednak, w sposób ograniczony, 357 wykorzystuje działania sponsoringowe - emituje nieliczne spoty i materiały „mecenasów” wspierających rozgłośnię finansowo, które pojawiają się w czasie wybranych audycji autorskich. W czerwcu 2021 roku Radio 357 było wspierane przez ponad 31600 patronów, zapewniających comiesięczne wpłaty na poziomie 675 tys. złotych ${ }^{15}$. Radio ma profil muzyczno-publicystyczny i — podobnie jak Radio Nowy Świat - koncentruje się na programach autorskich, nie emituje reklam (z wyjątkiem sytuacji opisanych powyżej) i nie zaprasza na rozmowy polityków. Ze względu na wiele niestandardowych działań nastawionych na zbliżenie się do słuchaczy (między innymi podkast „Jacy jesteśmy?” Michała Olszańskiego, w którym dziennikarze mówią sami o sobie, czy też udostępnienie słuchaczom autorskich playlist muzycznych w portalach streamingowych) Radio 357 prezentuje się jako dobrze rozumiejące społeczność internetową, interaktywne medium.

Tabela 2. Kanały streamingów Radia 357

\begin{tabular}{|l|l|l|}
\hline \multicolumn{1}{|c|}{ Aplikacje mobilne } & \multicolumn{1}{|c|}{ Platformy internetowe } & \multicolumn{1}{c|}{ Telewizje } \\
\hline Aplikacja Radio 356 & OpenFM & Telewizja kablowa Promax \\
(Google Play, App & WP Pilot & Telewizja kablowa Inea \\
Store) - obsługa & TuneIn & Radio+ dla abonentów \\
Chromecast i AirPlay \\
Patronite Audio (Google & MediaU & posiadających dekodery \\
Play, App Store) & YamahaMusicCast & CANAL+ podłączone do \\
Replaio Radio (Google & Frontier Nuvola & internetu (pod numerem \\
Play) - obsługa & Radio Browser & $569)$ \\
Chromecast & Radio Polska & \\
& Play Now & \\
\hline
\end{tabular}

Źródło: opracowanie własne.

\section{Metoda i przedmiot badania}

Przedmiotem analiz przeprowadzonych na potrzeby niniejszego artykułu jest zbiór krótkich tekstów opublikowanych przez stacje radiowe Radio Nowy Świat (RNS) oraz Radio 357 (357) w dziale poświęconym aktualnym wydarzeniom (w okresie 1 lutego-31 marca 2021 roku). Teksty te tworzą korpusy poddane analizie ilościowej i analizie jakościowej, a wyniki prowadzonych obserwacji zestawio-

14 J. Stawiany, Radio 357 prześcignęło Radio Nowy Świat w miesięcznym finansowaniu, https:// www.wirtualnemedia.pl/artykul/radio-357-przegonilo-radio-nowy-swiat-zbiorka-internetowa-patronite (dostęp: 10.06.2021).

15 https://patronite.pl/radionowyswiat (dostęp: 10.06.2021). 
ne zostały na zasadach komparatystyki ${ }^{16}$, co umożliwia wskazanie podobieństw i różnic w sposobie komunikowania się stacji z odbiorcami oraz dyskursywnych obszarów zainteresowań nadawców ${ }^{17}$. Dobór próby badania jest nieprobabilistyczny głównie ze względu na fakt, iż jedna z badanych stacji (Radio 357) prowadzi działalność od kilku miesięcy, dlatego też pod uwagę wzięte zostały pełne (stan na kwiecień 2021) miesiące, kiedy obie analizowane rozgłośnie działały. Pominięcie stycznia 2021 roku podyktowane jest rozpoczęciem działalności przez Radio 357 piątego dnia owego miesiąca (byłby to w analizie miesiąc niepełny czasowo), a także chęcią pominięcia potencjalnych komunikatów okazjonalnych (związanych ze startem rozgłośni lub problemami organizacyjno-technicznymi).

\section{Analiza ilościowa}

Dla zarysowania pełnego obrazu podstawy wyliczeń statystycznych istotne jest wskazanie, że liczba komunikatów wygenerowanych przez obie stacje radiowe w badanym przedziale czasowym jest niemal identyczna. Dla 357 wynosi siedem w lutym i cztery w marcu, a dla RNS odpowiednio osiem i cztery. Strukturalnie więc sprzyja proporcjonalnemu zestawieniu korpusów tekstowych pod względem ilościowym. Trzeba jednak zaznaczyć, iż mimo wspomnianego podobieństwa nie są to korpusy zgodne objętościowo. Komunikaty stworzone przez Radio 357 zawierają 1100 słów, podczas gdy komunikaty zamieszczone w tym samym okresie przez RNS zawierają ich 3041. Daje to niemal trzykrotnie więcej treści oferowanej odbiorcom tej ostatniej stacji.

By możliwe było porównanie zawartości obu korpusów, dane prezentowane są procentowo w odniesieniu do objętości, gdyż informacja jednostkowa (na przykład o częstości występowania słów) mogłaby być myląca w przypadku tak znacznej różnicy w liczbie słów.

Tabela 3. Średnia liczba słów przypadających na jedno zdanie w badanych komunikatach stacji radiowych: Radia Nowy Świat oraz Radia 357

\begin{tabular}{|l|c|c|c|}
\cline { 2 - 4 } \multicolumn{1}{c|}{} & Liczba słów & Liczba zdań & Średnia liczba słów w zdaniu \\
\hline 357 & 1100 & 132 & 8,3 \\
\hline RNS & 3041 & 221 & 13,8 \\
\hline
\end{tabular}

Źródło: opracowanie własne.

Z uwzględnionych w tabeli 3 danych wynika, że w komunikacji ze swoimi odbiorcami RNS posługuje się przeciętnie (według średniej) zdaniami bardziej roz-

16 Por. L. Krantz-Domasłowska, Konteksty badań komparatystycznych - temat i metoda, ,Acta Universitatis Nicolai Copernici. Zabytkoznawstwo i Konserwatorstwo" 43, 2012, s. 34-5.

17 Zob. T. Piekot, Refleksyjność jako autoidentyfikacja w Krytycznej Analizie Dyskursu, [w:] Dyskurs w perspektywie akademickiej, red. I. Uchwanowa-Szmygowa, et al., Olsztyn 2014, s. 99. 
budowanymi, dłuższymi, o większej liczbie słów. By jednak precyzyjnie prześledzić objętość poszczególnych tekstów w korpusie, należy odnieść się do liczby tworzących je znaków. Poniższe wykresy (wykres 1 i wykres 2) prezentują fluktuacje objętości komunikatów obu stacji na przestrzeni poddanych analizie dwóch miesięcy. Dostrzegalne są znaczne zmiany długości poszczególnych tekstów ze wskazaniem na nieco większą stabilizację w wypadku Radia 357.

W wypadku Radia Nowy Świat 5 lutego na stronie internetowej zamieszczono dwie wiadomości (znacznie różniące się między sobą długością), co dostrzegalne

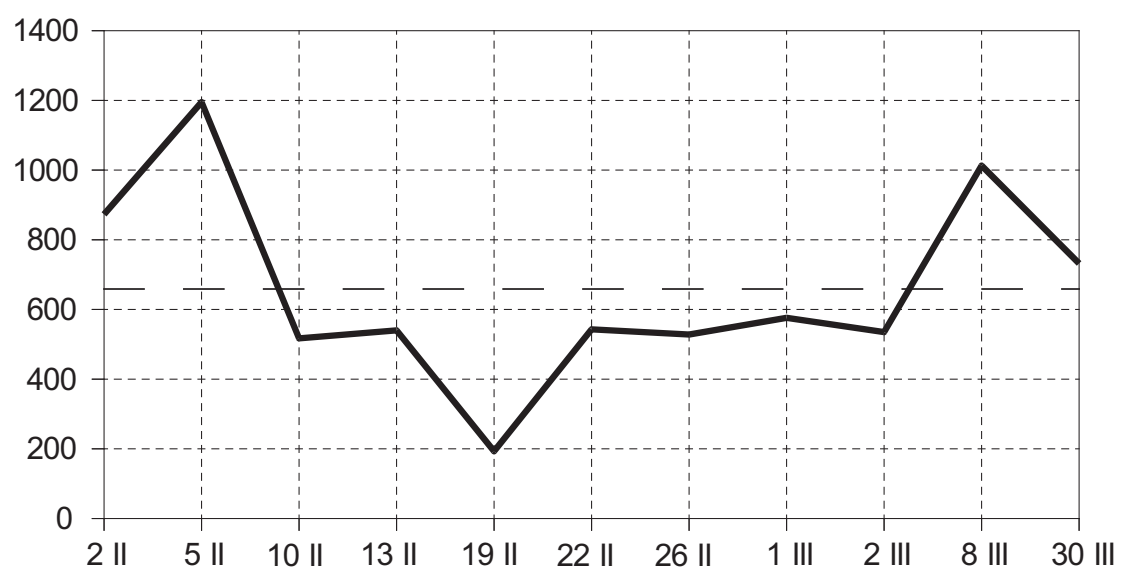

Wykres 1. Liczba znaków w poszczególnych komunikatach Radia 357 w badanym okresie (linią przerywaną zaznaczono wartość średnią 659 znaków)

Źródło: opracowanie własne.

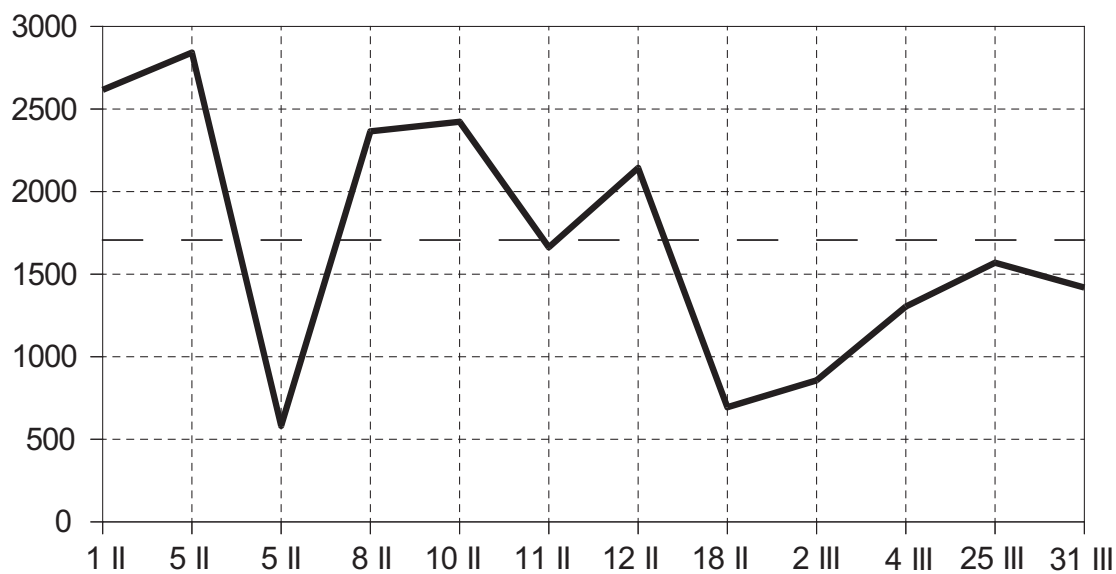

Wykres 2. Liczba znaków w poszczególnych komunikatach Radia Nowy Świat w badanym okresie (linią przerywaną zaznaczono wartość średnią 1706 znaków)

Źródło: opracowanie własne. 
jest w zestawieniu danych na wykresie 2 jako podwójna data 5 lutego. Wartości średnie zaznaczono poziomą linią przerywaną (szczegółowe dane liczbowe znajdują się w opisie wykresu).

Kolejną część opracowania stanowi analiza częstości występowania poszczególnych słów w korpusie. Do tego celu wykorzystane zostało narzędzie Text Analyzer, dostępne w trybie online za pośrednictwem witryny internetowej Online-Utility.org $^{18}$, na licencji freeware (niekomercyjnie ${ }^{19}$ ). Pozwala ono na wprowadzenie danych w postaci cyfrowej i otrzymanie zwrotu zliczenia w postaci tabelarycznej.

Ze względu na niewielkie rozmiary badanych zbiorów tekstów, jak też ich wielotematyczną zawartość (nie jest to zbiór tekstów specjalistycznych) udział procentowy powtarzających się słów — niebędących jednak spójnikami — osiąga często wartość ułamkową poniżej 1\%. Dlatego też dla wierniejszego odwzorowania danych wyliczenie zawiera wartości do czterech miejsc po przecinku, dzięki czemu wyraźniej widać, jak niewielkie różnice decydują o pozycji w zestawieniu.

W perspektywie statystycznej najistotniejsze wydają się słowa o największym współczynniku powtarzalności, zwłaszcza jeśli mamy do czynienia z korpusem o niewielkich rozmiarach, gdyż mogą wskazywać na dyskursywne zainteresowanie określonymi pojęciami lub tematami. Tabela 4 prezentuje zestawienie powtarzalności słów dla obu nadawców, ograniczone do 50 pierwszych pozycji (szeregowanych od największej liczby wystąpień w korpusie).

Tabela. 4. Zestawienie pierwszych 50 rekordów częstości występowania poszczególnych słów w badanych korpusach, z podziałem na Radio 357 oraz Radio Nowy Świat

\begin{tabular}{|c|c|c|c|c|c|c|}
\hline \multirow{2}{*}{ Lp. } & \multicolumn{3}{|c|}{357} & \multicolumn{3}{|c|}{ RNS } \\
\hline & słowo & wystąpienia & $\%$ & słowo & wystąpienia & $\%$ \\
\hline 1. & $\mathrm{w}$ & 38 & 3,4545 & $\mathrm{w}$ & 89 & 2,9267 \\
\hline 2. & $\mathrm{i}$ & 30 & 2,7273 & $\mathrm{i}$ & 69 & 2,2690 \\
\hline 3. & to & 24 & 2,1818 & na & 56 & 1,8415 \\
\hline 4. & o & 21 & 1,9091 & o & 52 & 1,7100 \\
\hline 5. & $\mathrm{z}$ & 20 & 1,8182 & się & 49 & 1,6113 \\
\hline 6. & na & 20 & 1,8182 & - & 46 & 1,5127 \\
\hline 7. & 0 & 15 & 1,3636 & nie & 43 & 1,4140 \\
\hline 8. & $\mathrm{a}$ & 12 & 1,0909 & to & 40 & 1,3154 \\
\hline 9. & od & 12 & 1,0909 & $\mathrm{z}$ & 35 & 1,1509 \\
\hline 10. & się & 12 & 1,0909 & do & 34 & 1,1181 \\
\hline 11. & do & 11 & 1,0000 & nowy & 30 & 0,9865 \\
\hline 12. & 357 & 9 & 0,8182 & świat & 28 & 0,9207 \\
\hline
\end{tabular}

18 https://www.online-utility.org/text/analyzer.jsp (dostęp: 30.04.2021).

19 https://www.online-utility.org/terms_of_use.jsp (dostęp: 30.04.2021). 


\begin{tabular}{|c|c|c|c|c|c|c|}
\hline \multirow{2}{*}{ Lp. } & \multicolumn{3}{|c|}{357} & \multicolumn{3}{|c|}{ RNS } \\
\hline & słowo & wystąpienia & $\%$ & słowo & wystąpienia & $\%$ \\
\hline 13. & już & 9 & 0,8182 & że & 19 & 0,6248 \\
\hline 14. & co & 7 & 0,6364 & będzie & 19 & 0,6248 \\
\hline 15. & godz & 7 & 0,6364 & co & 18 & 0,5919 \\
\hline 16. & będzie & 7 & 0,6364 & antenie & 18 & 0,5919 \\
\hline 17. & $\mathrm{za}$ & 6 & 0,5455 & jest & 18 & 0,5919 \\
\hline 18. & audycji & 6 & 0,5455 & tym & 18 & 0,5919 \\
\hline 19. & ale & 6 & 0,5455 & od & 17 & 0,5590 \\
\hline 20. & dla & 6 & 0,5455 & jak & 17 & 0,5590 \\
\hline 21. & jak & 6 & 0,5455 & już & 16 & 0,5261 \\
\hline 22. & tym & 6 & 0,5455 & dla & 15 & 0,4933 \\
\hline 23. & antenie & 5 & 0,4545 & a & 14 & 0,4604 \\
\hline 24. & radio & 5 & 0,4545 & radio & 14 & 0,4604 \\
\hline 25. & dzisiaj & 5 & 0,4545 & po & 13 & 0,4275 \\
\hline 26. & bez & 5 & 0,4545 & nas & 13 & 0,4275 \\
\hline 27. & nie & 5 & 0,4545 & przez & 13 & 0,4275 \\
\hline 28. & zapraszamy & 5 & 0,4545 & audycji & 12 & 0,3946 \\
\hline 29. & 1 & 4 & 0,3636 & czy & 12 & 0,3946 \\
\hline 30. & 3 & 4 & 0,3636 & które & 11 & 0,3617 \\
\hline 31. & 15 & 4 & 0,3636 & ale & 11 & 0,3617 \\
\hline 32. & 21 & 4 & 0,3636 & ich & 11 & 0,3617 \\
\hline 33. & po & 4 & 0,3636 & można & 10 & 0,3288 \\
\hline 34. & radia & 4 & 0,3636 & również & 10 & 0,3288 \\
\hline 35. & które & 4 & 0,3636 & świecie & 10 & 0,3288 \\
\hline 36. & że & 4 & 0,3636 & tak & 10 & 0,3288 \\
\hline 37. & osób & 4 & 0,3636 & bo & 9 & 0,2960 \\
\hline 38. & czyli & 4 & 0,3636 & państwa & 9 & 0,2960 \\
\hline 39. & bartek & 4 & 0,3636 & radia & 9 & 0,2960 \\
\hline 40. & audycje & 4 & 0,3636 & razem & 9 & 0,2960 \\
\hline 41. & mamy & 4 & 0,3636 & tylko & 9 & 0,2960 \\
\hline 42. & czy & 4 & 0,3636 & jeszcze & 8 & 0,2631 \\
\hline 43. & nas & 4 & 0,3636 & nowym & 8 & 0,2631 \\
\hline 44. & też & 4 & 0,3636 & czyli & 8 & 0,2631 \\
\hline 45. & g & 3 & 0,2727 & jednak & 8 & 0,2631 \\
\hline
\end{tabular}




\begin{tabular}{|c|l|c|c|l|c|c|}
\hline \multirow{2}{*}{ Lp. } & \multicolumn{3}{|c|}{357} & \multicolumn{3}{c|}{ RNS } \\
\cline { 2 - 7 } & \multicolumn{1}{|c|}{ słowo } & wystąpienia & $\%$ & słowo & wystąpienia & $\%$ \\
\hline 46. & by & 3 & 0,2727 & radiu & 7 & 0,2302 \\
\hline 47. & mbank & 3 & 0,2727 & który & 7 & 0,2302 \\
\hline 48. & są & 3 & 0,2727 & patronów & 7 & 0,2302 \\
\hline 49. & radiu & 3 & 0,2727 & będziemy & 7 & 0,2302 \\
\hline 50. & państwa & 3 & 0,2727 & może & 7 & 0,2302 \\
\hline
\end{tabular}

Źródło: opracowanie własne.

Pominąwszy spójniki, przyimki czy partykuły, które najczęściej zajmują wysokie pozycje na liście frekwencji, w tekście pozostaje kilka słów, na które warto zwrócić uwagę w kontekście niniejszego badania. Pierwszą grupę można określić jako słowa pośredniczące między językiem branżowym a autotematyzacją przekazu. W obydwu rozgłośniach najwyższe pozycje zajęły bowiem określenia stanowiące nazwę własną stacji (poz. 11 i 12 w tabeli 4). Struktura tej grupy słów jest bardzo podobna także na pozycjach dalszych — dobrym przykładem są tu słowa takie jak (wraz z odmianami gramatycznymi): radio, audycja, antena. Trudno pomijać je, gdy się mówi o radiofonii, gdyż stanowią immanentną część słownika profesjonalnego, lecz częste ich występowanie świadczyć może także o skłonności do poruszania w badanych komunikatach tematów związanych z własną rozgłośnią. Pozostawałoby to w zgodzie z umiejscowieniem owych elementów w strukturze strony internetowej — o czym więcej w części jakościowej.

Drugą grupą słów, odznaczających się wysoką pozycją na liście frekwencji, są słowa determinujące podmiotowość. O ile wyrwane z kontekstu określenia nie dają się łatwo wyłowić, o tyle zwraca uwagę podobieństwo w uplasowaniu się w przypadku obu nadawców słowa „nas”, odpowiadającego za poczucie wspólnotowości (redakcyjnej lub na osi słuchacze-redakcja), gdzie dla 357 jest to w przybliżeniu $0,4 \%$, a dla RNS $\sim 0,4 \%$. Tak samo wygląda statystyka zwrotu grzecznościowego „państwa” (357 0,3\% oraz RNS $\sim 0,3 \%$ ). Schemat jest bardzo podobny dla obu korpusów, z uwzględnieniem odrobinę większej reprezentacji idei oferty i współuczestnictwa reprezentowanej w słowach „mamy”, „,zapraszamy” po stronie Radia 357. W mniejszej liczbie punktów procentowych odpowiada jej słowo ,razem” w Radiu Nowy Świat, jednakże można mu przypisać wyraźniejszy semantyczny wskaźnik wspólnotowości. Interesującą różnicą, wywodzącą się między innymi ze struktury finansowej stacji, jest obecność określenia słuchaczy „patronami” (RNS - siedmiokrotnie), czego zupełnie brak w pierwszej pięćdziesiątce 357. Jednakże o ile wspomniane słowo jest raczej ogólnikowe i nie odnosi się do żadnej instytucji, o tyle Radio 357 trzykrotnie przywołuje konkretną nazwę sponsora (wynika z kontekstu) „mBank” w korpusie swoich komunikatów. 
Ostatnią grupę ważnych w kontekście tabeli 4 słów stanowią określenia czasowe. Zarówno dosłowne, na przykład wskazania godzinowe „godz.” (357), jak i występujące w obu rozgłośniach stwierdzenia wyznaczające perspektywy czasowe dla kontekstu zdań, takie jak: „są”, „dzisiaj”, „,będzie” (357), ,jest”, „,będzie”, „,będziemy” (RNS). Co interesujące, wskazują na realizowany przez jednego i drugiego nadawcę wektor czasowy stawiający na zainteresowanie teraźniejszością i nadchodzącą przyszłością. Brakuje wskazań do retrospekcji czy reminiscencji. Być może związane jest to z ideą nowości, świeżości i nowatorskiej (ergo skupionej na przyszłości) ofercie programowej stacji radiowych działających na rynku od niedawna.

\section{Analiza jakościowa}

Na wstępie niniejszej części analizy należy zarysować kwestię istotną z punktu widzenia interpretacji jakościowej badanych tekstów. Zarówno Radio 357, jak i Radio Nowy Świat umieszczają teksty na swoich stronach internetowych w sekcji implikującej niejako profil czy rodzaj komunikatu, z którym odbiorca ma do czynienia. Dla 357 jest to dolna część strony głównej, pod nagłówkiem „Co u nas nowego" ${ }^{20}$, dla RNS zaś — „Aktualności” znajdujące się w podmenu „O nas”21. Można tym samym spodziewać się profilowania zamieszczanych tam tekstów jako autotematycznych bądź przynajmniej w jakimś stopniu traktujących o ,życiu" redakcji.

Po przeprowadzeniu analizy jakościowej tekstu okazuje się, że tego rodzaju zogniskowanie na własnej rozgłośni (traktowane jako temat globalny) istotnie występuje. Otwiera niejako pulę podobieństw między badanymi korpusami.

\subsection{Podobieństwa}

Dwa najważniejsze, a zarazem najobszerniejsze objętościowo, obszary o zbliżonym wydźwięku w przypadku każdej z badanych rozgłośni to autotematyzm (content) oraz kwestia roli słuchacza w układzie stworzonym przez medium, a raczej jego redakcję oraz odbiorcę — indywidualnego oraz współtworzącego wspólnotę adresatów komunikatu stacji.

Wśród elementów tekstu, które można zakwalifikować do obszaru autotematyczności, struktura czy profil komunikacyjny obu stacji radiowych kształtują się bardzo podobnie. W obu zbiorach tekstów pojawiają się wątki dotyczące roz-

20 https://radio357.pl/ (dostęp: 1.05.2021).

21 https:/nowyswiat.online/kategoria/wiadomosci/ (dostęp: 1.05.2021). 
woju rozgłośni ${ }^{22}$, trudności związanych z pracą redakcji ${ }^{23}$, napotkanych problemów i odnoszonych sukcesów ${ }^{24}$. Co interesujące, treść badanych ,„aktualności” zawiera także swoiste wskazania o charakterze fundamentalnym, pozwalające na zorientowanie się odbiorcy $\mathrm{w}$ aksjologii wyznawanej przez medium, poddające eksplanacji postawy oraz stosunek wobec określonych problemów. Ich skala jest zróżnicowana, od prostych przekonań do ważnych problemów społecznych. Dla Radia 357 są to na przykład zdania: „Nie wyobrażamy sobie życia bez książek! A tym bardziej ramówki Radia 357 bez rozmów o nich”, „chcemy włączyć się w tę ważną dla nas debatę. Wierzymy w to, że media powinny być wolne i niezależne. W tych sprawach powinniśmy mówić jednym głosem”. Podobnie temat ten realizuje Radio Nowy Świat, na przykład: „Radio pozostanie wierne kla sykom i jednocześnie jeszcze szerzej niż dotychczas otworzy się na nową muzykę, nowe trendy i artystów, którzy ukształtują przyszłość”, „Radio Nowy Świat sprzeciwia się wszelkim próbom osłabienia mediów, które i tak przez pandemię są w trudnej sytuacji”, „wszystkim nam zależy na tym, aby wiedzę jednak szerzyć, tę obywatelską również [...]".

22 357: „Radio intensywnie się rozwija”, „Pomagają nam tworzyć radio i treści wysokiej jakości”, „W Państwa głośnikach po raz pierwszy pojawił się serwis informacyjny Radia 357! I tak będzie już codziennie”, „mamy coś specjalnego. Pierwszy w historii naszej rozgłośni SoundClash357, czyli muzyczny dialog całej czwórki autorów”, „Publicystyka w ramówce 357 rośnie w siłę! Startujemy z wieczornym pasmem publicystycznym”; RNS: „w najbliższy wtorek pojawi się nowa audycja [...]”, „Redakcja muzyczna w Radiu Nowy Świat ma nowego szefa”, „Czy Nowy Świat może nadawać jeszcze dłużej? Może — i będzie. Czy może zaproponować więcej autorskich audycji? Może - i proponuje”, „głosów, weny i rozeznania w muzycznym świecie użyczyło aż czternaścioro młodych talentów Nowego Świata”.

23 357: „Rękawy mam już podwinięte i sprawy na pewno przyspieszą — mówi Bartek. Największym wyzwaniem jest stworzenie systemu do głosowania [...]. Musimy jeszcze odpowiedzieć na parę strategicznych pytań [...]”, „Od teraz codziennie gramy dłużej, aż do północy. Wydłużenie ramówki to nie takie proste zadanie. To zawsze praca zespołowa. Dyskutowaliśmy, szukaliśmy pomysłów na audycje i autorów, którym można je powierzyć.”; RNS: „Nie emitujemy reklam, nie finansuje nas żaden wielki podmiot”, „Nasze radio nie zaprzestało nadawania, bo od samego początku utrzymuje się tylko dzięki wpłatom naszych Patronów i nie emitujemy reklam”, „udało się nam poruszyć wiele istotnych kwestii prawnych, których objaśnienia nie są zawsze tak oczywiste, jak mogłoby się wydawać".

24 357: „10 dziennikarzy i reporterów w Polsce oraz korespondentów w 9 krajach. I ambicja, by zrobić to najlepiej jak potrafimy. Startujemy z wysokiego C”, „W tym czasie wyemitowaliśmy 250 audycji, a na antenie odtworzonych zostało około 10000 piosenek. W Radiu 357 na dzisiaj pracuje 43 dziennikarzy — twórców, którzy pojawiają się na antenie. Mamy też 8 wydawców, 14 osób, które tworzą radio od zaplecza, a biurem zajmuje się 6 osobowy zespół. To już całkiem poważna ekipa :)”; RNS: „Gwarantujemy Wam dobrą muzykę, gości, których znacie i szanujecie oraz tych, o których jeszcze nie wiedzieliście, że chcieliście poznać. Przedstawimy ich Wam. Spotkamy się razem w domowym zaciszu, w samochodzie, przy pracowym biurku. W słuchawkach i głośnikach. W telefonie, komputerze — jak kto woli”. 
Ostatnim ważnym składnikiem obszaru autotematyczności jest posłużenie się — w kontekście prezentowania własnej oferty programowej - figurą autorytetu (eksperckiego ${ }^{25}$ bądź opartego na popularności). W Radiu 357 przeważa stawianie członków redakcji w roli agensa wykonywanych czynności (,[Paulina Wilk — przyp. J.W., Ł.Ś.] poprowadzi [...]”, „Barbara Włodarczyk [...] opowie [...]”, „za mikrofonami zasiądzie Tomasz Jeleński i porozmawia z gośćmi [...]”, „Tomek Michniewicz zbierze [...]”), co implikuje dyskursywnie aktywność nadawcy i zdolność do podejmowania działania, inicjatywy. Tymczasem Radio Nowy Świat eksponuje gości - zazwyczaj osoby rozpoznawalne w sferze publicznej — podkreślając ich walor ekspercki, profesjonalny, bazując często na wizerunku danej osoby (,niebawem powitamy na antenie Mistrza [...]”, „na naszej antenie pojawi się profesor Jerzy Bralczyk. Felietonów jednego z najwybitniejszych polskich językoznawców będzie można posłuchać co tydzień [...]”, ,,jej [Olgi Tokarczuk — przyp. J.W., Ł.Ś.] zgoda na rozmowę w Radiu Nowy Świat — o życiu kobiety we współczesnym świecie - jest wielkim wydarzeniem, na które czekamy z niecierpliwością”, „Mistrzyni aktorstwa i dzielenia się dobrem. Anna Dymna zaprosi do swojego muzycznego świata [...]”, „Mistrzyni przejmie antenę. Jak wygląda muzyczny świat Urszuli Dudziak?").

Wynikająca dyskursywnie z tekstu rola słuchacza - a więc taka, jaką nadają mu twórcy radiowego contentu, jest zbliżona w obu korpusach. Twórcy komunikatów niejednokrotnie podkreślają zależność przetrwania ich medium na rynku od decyzji słuchaczy o udzieleniu finansowego wsparcia ${ }^{26}$. Model współuczestnictwa w kreowaniu i kształtowaniu działań rozgłośni realizuje się na poziomie zachęcania do aktywności twórczej ${ }^{27}$, a także doceniania tej wykazanej przez odbiorców dotychczas ${ }^{28}$. Zdanie słuchaczy-współtwórców radia w tym kontekście nabiera dużego znaczenia i jest dla redakcji istotne.

25 357: „chcemy oddać głos przedstawicielom różnych redakcji i medioznawcom”; RNS: „Na te i wiele innych pytań odpowiadali eksperci-sędziowie na naszej antenie".

26 357: „Czy będzie ciąg dalszy? Wszystko w Państwa rękach!”; RNS: „Utrzymujemy się jedynie z Waszych wpłat. Wasza, Drodzy Słuchacze, zasługa. To od Was zależy, a bez Was i Waszego wsparcia — nie będzie nas w ogóle”, „swoimi wpłatami realnie dołożyć się do sukcesu Radia Nowy Świat".

27 357: „To wyzwanie dla antenowych detektywów. Słuchajcie uważnie audycji muzycznych w ten weekend. Snujcie domysły [...]”, „Lista była dobrą zabawą, plebiscytem, odzwierciedleniem muzycznych gustów i wyborów Słuchaczy [...]”; RNS: „Państwa zadaniem jest wybrać dwa słowa, które się w nim pojawią — i tym samym ustawią, jak by nie patrzeć, jego fabulę”, ,słuchacze zadadzą pytania - my przekażemy je ekspertom i wrócimy z antenowa odpowiedzią”, „Jesteśmy radiem, które nie tylko gra dla Słuchaczy, ale też wspólnie z nimi”.

28 357: „wyczekiwanie Państwa reakcji [...]”, „Dziękujemy, że dali się Państwo namówić [...]”, „Dziękujemy, że dzięki Państwu możemy tworzyć właśnie takie radio!”; RNS: „,ucieszył nas (nas redakcję) tak pozytywny odbiór cyklu”, „po takich Odbiorcach, takich Słuchaczach, można spodziewać się tak naprawdę tylko jednego - mądre treści zawsze będą w cenie”. 
Jako końcowa uwaga o podobieństwach między badanymi rozgłośniami pojawia się kwestia stricte językowa. O ile język komunikatów nie jest nigdy formalny czy oficjalny, o tyle unika także (mimo swojej prostoty) sformułowań nieakceptowanych w przestrzeni komunikowania publicznego. Niemniej posiłkowanie się stylem potocznym jest sporadyczne, a przykłady takowego uznać należy za akcydentalne ${ }^{29}$.

\subsection{Różnice}

Analizowany materiał wykazuje także pewne różnice na poziomie dyskursywnym, a głównym zagadnieniem jest konwencja poruszania tematu „patronów" (w domyśle: sponsorów) rozgłośni. Ze względu na sposób finansowania rola wspomnianych ,patronów” (takim określeniem posługują się konsekwentnie obie stacje) jest niebagatelna, a przekaz zawarty w komunikatach zdaje się to potwierdzać - eksplicytnie lub pośrednio. O ile RNS posługuje się tym ogólnym pojęciem, o tyle w wypadku 357 w jednym z tekstów pada nazwa firmy, która jest sponsorem działalności stacji ${ }^{30}$. Znacznie bardziej rozbudowana jest kwestia sponsoringu w RNS, gdzie bycie członkiem grupy sponsorskiej (implikacja zamkniętej, elitarnej wspólnoty skupionej wokół określonej aksjologii ${ }^{31}$ ) generuje pewnego rodzaju przywileje ${ }^{32}$, a stacja traktuje je jako kartę przetargową w walce o wsparcie ekonomiczne, podkreślając jednocześnie, że ze zdaniem swoich darczyńców się liczy ${ }^{33}$.

W warstwie strukturalnej odnaleźć można także kilka elementów różniących stacje w sposobie organizowania treści badanych komunikatów. Pierwszym z nich jest tytułowanie poszczególnych wiadomości — obecne w Radiu Nowy Świat, podczas gdy w drugiej stacji tytułów brak. Jeśli zaś spojrzeć pod kątem gatunkowym, w rozbudowanych tekstach RNS pojawia się oddanie głosu bohaterowi teks-

29 357: „Jak minął Państwu miesiąc z nami? Bo nam z Państwem szybko i niesamowicie. Bez dwóch zdań zapamiętamy go na całe życie :)”, „spadliśmy z krzesła z wrażenia ;)”; RNS: „znamy się na tej robocie - ale to Wy wiecie najlepiej [...]”, „No dobra, nie wygłupiajmy się: co Państwo robią w wolnym czasie, jakie mają pasje, zainteresowania i jak się Państwu życie ułożyło — ok, teraz forma się zgadza. Lecimy dalej, bo tu o nowy cykl chodzi”.

30 357: „naszym dyskusjom publicystycznym patronuje mBank Intensive”. „To audycje dla osób ciekawych świata, które chcą wiedzieć i widzieć więcej. Wartości te są też bliskie mBank Intensive $[\ldots] "$ ".

31 RNS: „W grupie zamkniętej Radia Nowy Świat dostępny jest formularz zgłoszeniowy, który należy wypełnić i odesłać”. „Jako Patron otrzymasz dostęp do naszych podcastów, będziesz na bieżąco z najnowszymi informacjami o Radiu oraz dołączysz do grupy na Facebooku, gdzie dyskusje trwają całą dobę".

32 RNS: „A Państwa oczywiście zachęcamy do głosowania. Jednak uwaga — wybierać będą mogli tylko nasi Patroni”, „Spróbować będzie mógł każdy patron. Nieważna jest kwota wpłaty, najważniejsza jest osobowość i ciekawa historia".

33 RNS: „Nadajemy więc dalej, bo nasi Patroni mogliby poczuć się zawiedzeni, ale oczywiście o proteście informujemy”, ,[...] o tym, co dla naszych Patronów ważne”. 
tu za pomocą (często rozległych) cytatów, jak też biogram — nieobecny w żadnym tekście 357 w obrębie korpusu.

Kolejna różnica to obecność w RNS jednego tekstu poświęconego w całości zespołowi Kwiat Jabłoni — goszczącemu na antenie radia — w którym poza retrospekcją wydarzenia, umieszczone zostały fragmenty wypowiedzi członków zespołu w formie audio (implementowany player). W wypadku 357 sekcja aktualności nie ma funkcji odtwarzania materiałów audio (stan na kwiecień 2021).

Ostatnią różnicą formalną jest użycie przez Radio 357 w treści komunikatów emotikonów oraz hashtagów ${ }^{34}$ - co może nawiązywać do nowoczesności rozgłośni — gdy zabiegu takiego nie znajdziemy w Radiu Nowy Świat (dotyczy badanego korpusu).

\section{Podsumowanie}

Radio 357 i Radio Nowy Świat to stacje o wielu podobieństwach natury zarówno organizacyjno-formalnej, jak i dyskursywnej. Struktura komunikatów umieszczanych w charakterze ,,aktualności” na stronach internetowych wskazuje na zainteresowanie tych podmiotów nowoczesnością, wektorem problematyki zakotwiczonym w teraźniejszości i skierowanym ku przyszłości, wysokim usytuowaniem roli słuchacza-patrona w procesie tworzenia contentu, a także znacznym skoncentrowaniem na sobie (to znaczy prezentowaniu treści ściśle związanych z daną stacją - autotematyczność). Jednocześnie RNS oferuje odbiorcy przekaz bardziej rozbudowany, obszerniejszy, wzbogacony o różne formy gatunkowe, podkreślając jednak formułę zamkniętego kręgu, którego członkowie mają określone przywileje. Unikalnym aspektem komunikacji w 357 jest stosowanie nowoczesnych form (emotikony, hashtagi), co może przesuwać uwagę w stronę młodszego odbiorcy, przy jednoczesnym zachowaniu prostoty formy (brak materiałów audio implementowanych w teksty). Należy pamiętać, że ten ostatni czynnik może być związany z krótkim stażem stacji na rynku radiowym.

Obie stacje radiowe zdają się jednak doskonale rozumieć, że mają do czynienia z nowym typem odbiorcy-słuchacza.

Odbiorca ten zamienia się w użytkownika, co podkreślić ma jego aktywność niezbędną do udziału w komunikacji. Może on nie tylko konstruować hipertekst dla siebie, może również w każdej chwili formułować własne wypowiedzi, które wchodzą do zasobu całej sieci, a także współdziałać w zbiorowych projektach ${ }^{35}$.

Wiele działań podejmowanych zarówno przez Radio 357, jak i Radio Nowy Świat wyraźnie odpowiada potrzebom dzisiejszego użytkownika i cały czas zmieniającego się internetu — coraz bardziej złożonej sieci węzłów i wzajemnych za-

34 357: „\#GramyDluzej”, „\#22357”.

35 M. Hopfinger, Rekonfiguracja komunikacji społecznej, [w:] Internetowe gatunki dziennikarskie, red. K. Wolny-Zmorzyński, W. Furman, Warszawa 2010, s. 18. 
leżności (opisywanych już wiele lat temu przez cytowanego na początku tego artykułu Manuela Castellsa). Współczesnym trendom komunikacji online zdają się odpowiadać także specyfika i struktura analizowanych w artykule paratekstów o charakterze radiowych ,aktualności”.

\section{Bibliografia}

Castells M., Społeczeństwo sieci, Warszawa 2007.

Hopfinger M., Rekonfiguracja komunikacji spotecznej, [w:] Internetowe gatunki dziennikarskie, red. K. Wolny-Zmorzyński, W. Furman, Warszawa 2010.

Kerckhove de D., Inteligencja otwarta. Narodziny społeczeństwa sieciowego, Warszawa 2001.

Kranz-Domasłowska L., Konteksty badań komparatystycznych — temat i metoda, „Acta Universitatis Nicolai Copernici. Zabytkoznawstwo i Konserwatorstwo" 43, 2012.

Loewe I., Gatunki paratekstowe w komunikacji medialnej, Katowice 2007.

Piekot T., Refleksyjność jako autoidentyfikacja w Krytycznej Analizie Dyskursu, [w:] Dyskurs w perspektywie akademickiej, red. I. Uchwanowa-Szmygowa, M. Sarnowski, T. Piekot, M. Poprawa, G. Zarzeczny, Olsztyn 2014. 